\title{
On the thermal-hydraulic performances of the DEMO divertor cassette body cooling circuit equipped with a liner
}

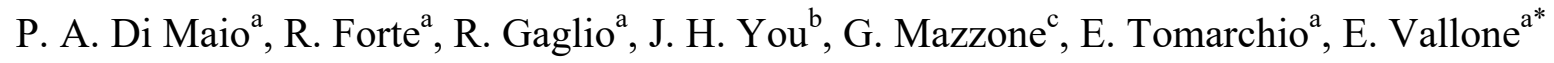 \\ ${ }^{a}$ Department of Engineering, University of Palermo, Viale delle Scienze, Ed. 6, 90128 Palermo, Italy \\ ${ }^{b}$ Max Planck Institute of Plasma Physics (E2M), Boltzmann Str.2, 85748 Garching, Germany \\ ${ }^{c}$ Department of Fusion and Technology for Nuclear Safety and Security, ENEA C.R. Frascati, via E. Fermi 45, 00044 \\ Frascati (Roma), Italy
}

In the framework of the Work Package DIV 1 - "Divertor Cassette Design and Integration" of the EUROfusion action, a research campaign has been jointly carried out by University of Palermo and ENEA to investigate the steady-state thermal-hydraulic performances of the DEMO divertor cassette cooling system. The research activity has been focussed onto the most recent design of the Cassette Body (CB) cooling circuit, consistent with the DEMO baseline 2017 and equipped with a liner, whose main function is to protect the underlying vacuum pump hole from plasma radiation. The research campaign has been carried out following a theoretical-computational approach based on the finite volume method and adopting the commercial Computational Fluid-Dynamic (CFD) code ANSYS-CFX.

The CB thermal-hydraulic performances have been assessed in terms of coolant and structure temperature, coolant overall total pressure drop and flow velocity distribution, mainly in order to check its aptitude to provide a uniform and effective cooling to both CB and liner structures. Moreover, the margin against coolant saturation has been evaluated in order investigate whether any risk of its bulk vaporisation is prevented.

The outcomes of the study have shown some criticalities, mainly in terms of structure maximum temperature and coolant vaporization occurrence within the liner. As a consequence, some minor design variations have been suggested within the paper.

Models, loads and boundary conditions assumed for the analyses are herewith reported and critically discussed, together with the main results obtained.

Keywords: DEMO, divertor, cassette body, CFD analysis, thermofluid-dynamics.

\section{Introduction}

The recent European roadmap, drafted to realize commercially viable fusion power generation, has defined reliable power exhausting as one of the most critical missions. Heat-exhaust systems must be capable of withstanding the large heat and particle fluxes of a fusion power plant, allowing, at the same time, as high performance as possible from the core plasma [1].

The divertor is the key in-vessel component to accomplish this mission as it is responsible for power exhaust and impurity removal via guided plasma exhaust. As a consequence, the divertor has to sustain very high heat and particle fluxes arising from the plasma (up to $20 \mathrm{MW} / \mathrm{m}^{2}$ ), while experiencing an intense nuclear deposited heat power, which could jeopardize its structure and limit its lifetime. Therefore, attention has to be paid to the thermal-hydraulic design of its cooling system, in order to ensure a uniform and proper cooling, without an unduly high pressure drop.

Within the framework of the Work Package DIV 1 "Divertor Cassette Design and Integration" of the EUROfusion action $[2,3]$ and in line with previous activities [4-6], in 2018 a research campaign has been jointly carried out by University of Palermo and ENEA to theoretically assess the steady-state thermal-hydraulic performances of the DEMO divertor cassette cooling system, focussing the attention on the Cassette Body (CB) cooling circuit.
A theoretical-numerical approach based on the finite volume method has been followed adopting the commercial Computational Fluid-Dynamic (CFD) code ANSYS CFX v.19.2 [7], previously used in similar studies [8] and adopted to evaluate concentrated hydraulic resistances to be used in system codes $[9,10]$.

During 2018, CFD analyses have been carried out to investigate the steady-state thermal-hydraulic performances of the latest water-cooled $\mathrm{CB}$ design equipped with a shielding structure called liner. In addition, the aptitude of the cooling circuit to provide a uniform and effective cooling to both $\mathrm{CB}$ and liner structures has been assessed and potential solutions devoted to its improvement have been suggested. The assumptions relevant to these thermal-hydraulic analyses are herein reported and critically discussed, together with the main results obtained.

\section{Cassette body thermal-hydraulic analysis}

The DEMO divertor configuration has recently been adapted to the DEMO Baseline 2017 [11]. Conversely to the previous one, articulated in 54 toroidal cassettes, this new divertor concept is articulated in 48 cassettes, each composed of a $\mathrm{CB}$, equipped with a shielding liner and supporting two Plasma Facing Components (PFCs), namely an Inner Vertical Target (IVT) and an Outer Vertical Target (OVT) (Fig. 1) [12]. 


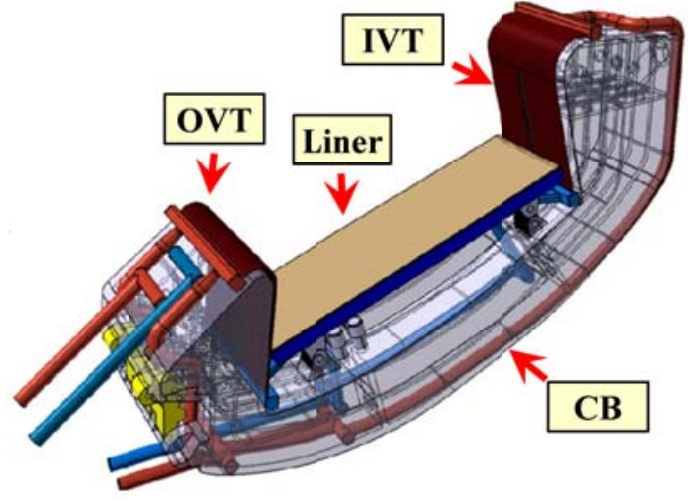

Fig. 1. DEMO divertor cassette 2018 configuration.

The CB is intended to support PFCs and shield Vacuum Vessel (VV) from irradiation. Therefore, in order to remove its nuclear deposited heat power, it is endowed with an active cooling circuit relying on the use of subcooled pressurized water at the inlet pressure and temperature of $3.5 \mathrm{MPa}$ and $180^{\circ} \mathrm{C}$, respectively, flowing with a thermal rise of $\approx 30^{\circ} \mathrm{C}[13]$.

\section{CB cooling circuit CFD analysis}

The thermal-hydraulic performances of the CB cooling circuit have been assessed by running a steadystate, fully coupled fluid-structure, thermofluid-dynamic analysis under the operative conditions in Table 1.

Table 1. Summary of coolant operative conditions.

\begin{tabular}{lc}
\hline & Conditions \\
\hline Inlet Temperature/Pressure & $180^{\circ} \mathrm{C} / 3.5 \mathrm{MPa}$ \\
$\Delta \mathrm{T}\left[{ }^{\circ} \mathbf{C}\right]$ & $\approx 30$ \\
$\mathbf{G}$ per Cassette $[\mathrm{kg} / \mathrm{s}]$ & 22.08 \\
\hline
\end{tabular}

To this purpose, a sensitive analysis has been carried out to select the geometric discretization of fluid and structure domains allowing grid-independent results to be obtained saving calculation time. Selected mesh parameters are reported in Table 2 and a detail of the mesh selected is shown in Fig. 2. Main assumptions, models and Boundary Conditions (BCs) adopted for the analysis are reported in Table 3.

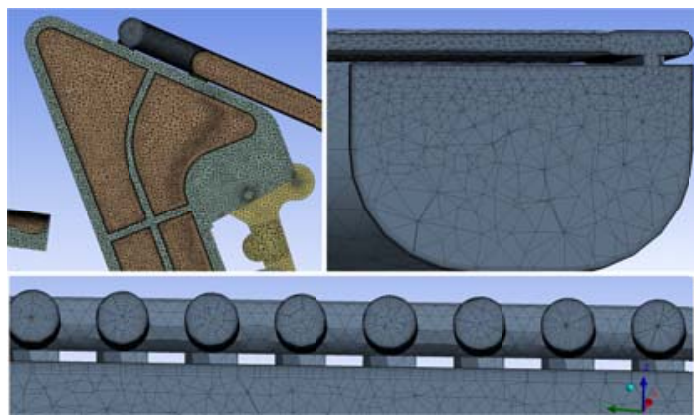

Fig. 2. Details of the mesh selected for calculations.
Table 2. Summary of the main mesh parameters.

\begin{tabular}{llc}
\hline Region & \multicolumn{1}{c}{ Mesh Parameter } & Value \\
\hline \multirow{6}{*}{ Fluid } & Nodes & $1.6010^{+7}$ \\
& Elements & $3.8310^{+7}$ \\
& Inflation Layers Number & 12 \\
& Liner/CB First Layer Height $[\boldsymbol{\mu m}]$ & $20 / 200$ \\
& Layers Growth Rate & 1.4 \\
& Typical Element Size [m] & $6.67 \cdot 10^{-3}$ \\
& Surface with y $\mathbf{y}^{+}<\mathbf{2 0 0}[\%]$ & 94 \\
\hline \multirow{2}{*}{ Structure } & Nodes & $5.1910^{+6}$ \\
& Elements & $2.0810^{+7}$ \\
\hline
\end{tabular}

Table 3. Summary of assumptions, models and BCs.

\begin{tabular}{lc}
\hline Analysis Type & Steady-state \\
& Water IAPWS IF97 [14] \\
Material Library & EUROFER [15] \\
& $\mathrm{W} / \mathrm{Ni}$-Al-Bronze [16] \\
& $316 \mathrm{~L}(\mathrm{~N}) \mathrm{SS} / \mathrm{SS} 660[16]$ \\
Heat Flux / Nuclear Heating & $0.5 \mathrm{MW} / \mathrm{m}^{2} / \mathrm{Non}$ uniform \\
Radiative Heat Transfer & Towards VV @ 40 $40^{\circ} \mathrm{C}$ \\
$\begin{array}{l}\text { Turbulence Model } \\
\text { Boundary Layer Modelling }\end{array}$ & $\mathrm{Scalable} \mathrm{Wall} \mathrm{Functions}$ \\
Wall Roughness & $15 \mu \mathrm{m}$ \\
Inlet BC & $\mathrm{T}=180^{\circ} \mathrm{C} / \mathrm{p}_{\mathrm{s}}=3.5 \mathrm{MPa}$ \\
Outlet BC & $\mathrm{G}=22.08 \mathrm{~kg} / \mathrm{s}$ \\
\hline
\end{tabular}

As to nuclear heating data, the non-uniform distribution of nuclear-deposited heat power density calculated by ENEA [17] has been adopted (Fig. 3).

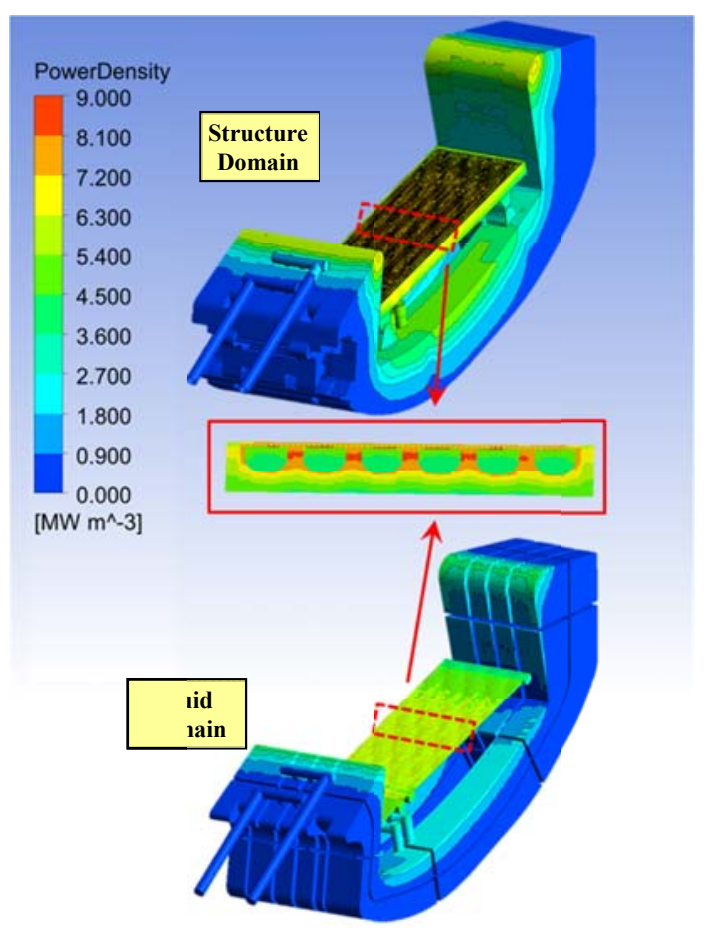

Fig. 3. Nuclear heating distribution adopted for calculations. 
A detailed breakdown of the total deposited power is reported in Table 4. Moreover, the complex heat transfer process towards $\mathrm{VV}$ has been roughly simulated by means of a radiative condition towards the VV heat sink, uniformly assumed at $40{ }^{\circ} \mathrm{C}$ (according to [18]).

Table 4. Deposited power breakdown.

\begin{tabular}{lc}
\hline & Power per Cassette [MW] \\
\hline Liner Surface & 0.718 \\
Liner Armour & 0.076 \\
Cassette Structure & 1.653 \\
Cassette Coolant & 0.760 \\
TOTAL & 3.206 \\
\hline
\end{tabular}

\subsection{Results}

A steady-state, fully coupled fluid-structure, thermofluid-dynamic analysis of the water-cooled CB cooling circuit has been carried out assessing its thermalhydraulic performances in terms of coolant and structure temperature, coolant total pressure and flow velocity distributions and coolant margins against saturation and Critical Heat Flux (CHF) occurrence.

Thermofluid-dynamic calculations have allowed to check whether the performances of the investigated CB configuration comply with the corresponding limits [13], paying a particular attention to fluid and structure temperature fields. In fact, the fluid should not reach the saturation temperature to avoid the occurrence of bulk saturation in any part of its domain. Furthermore, the structure, made in EUROFER, should not overcome the temperature of $550{ }^{\circ} \mathrm{C}$ [19].

The main results obtained are reported in Table 5, summarizing the coolant thermal rise and total pressure drop between inlet and outlet sections (Fig. 4), the total pumping power needed to route the coolant inside the $\mathrm{CB}$ cooling circuit and the maximum temperatures predicted for both the coolant and the steel structure.

Table 5. Summary of CB thermofluid-dynamic analysis results.

\begin{tabular}{lc}
\hline$\Delta \mathrm{p}[\mathrm{MPa}]$ & 1.383 \\
Pumping Power $[\mathrm{kW}]$ & 35.58 \\
$\Delta \mathrm{T}_{\text {fluid }}\left[{ }^{\circ} \mathrm{C}\right]$ & 32.75 \\
$\left(\mathrm{~T}_{\text {fluid }}\right)_{\text {Max }}\left[{ }^{\circ} \mathrm{C}\right]$ & $\mathbf{3 3 3 . 4 6}$ \\
$\left(\mathrm{T}_{\text {structure }}\right)_{\text {Max }}\left[{ }^{\circ} \mathrm{C}\right]$ & $\mathbf{1 4 1 9 . 1 8}$ \\
\hline
\end{tabular}

As it may be deduced from the analysis of Table 5, the overall hydraulic performances of the $\mathrm{CB}$ cooling circuit result partially acceptable, its overall total pressure drop being slightly lower than the prescribed limit of $1.4 \mathrm{MPa}$ and the estimate pumping power resulting $\approx 36 \mathrm{~kW}$ per cassette, for a total of $\approx 1708 \mathrm{~kW}$ (48 cassettes). Nevertheless, the heat removal aptitude of the same circuit shows some critical issues. In fact, even if the overall coolant thermal rise amounts to $\approx 33{ }^{\circ} \mathrm{C}$, \# letting the coolant exit the circuit with a bulk temperature slightly higher than $212{ }^{\circ} \mathrm{C}$, the coolant and the structure experience locally very high temperatures, suggesting the occurrence of local vaporization and thermal crisis.

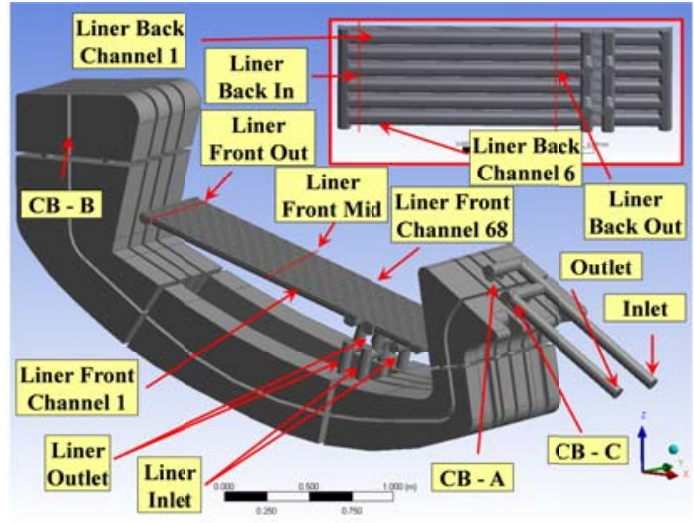

Fig. 4. CB cooling circuit main sections.

As to the fluid domain, total pressure, temperature and margin against saturation distributions are reported in Figs. 5-7. In particular, margin against saturation, defined as $\mathrm{T}_{\text {sat }}(\mathrm{p})-\mathrm{T}$ with $\mathrm{T}_{\text {satt }}(\mathrm{p})$ drawn from [20], has been reported in Fig. 7, where grey spots indicate surfaces where vaporization is predicted to occur.

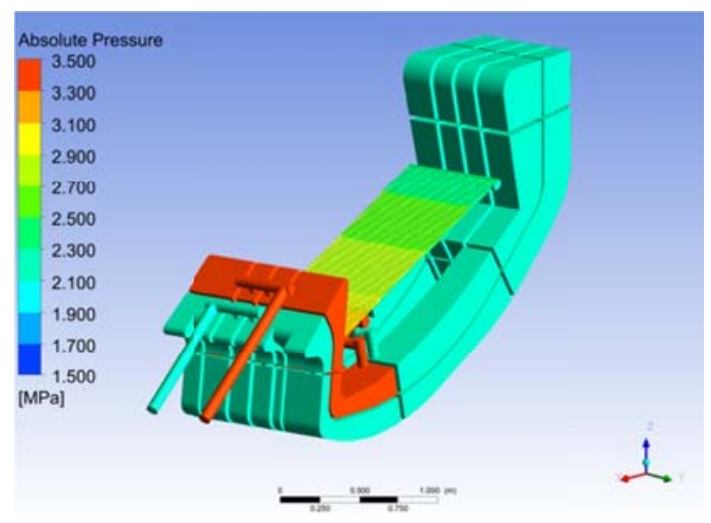

Fig. 5. Coolant total pressure field.

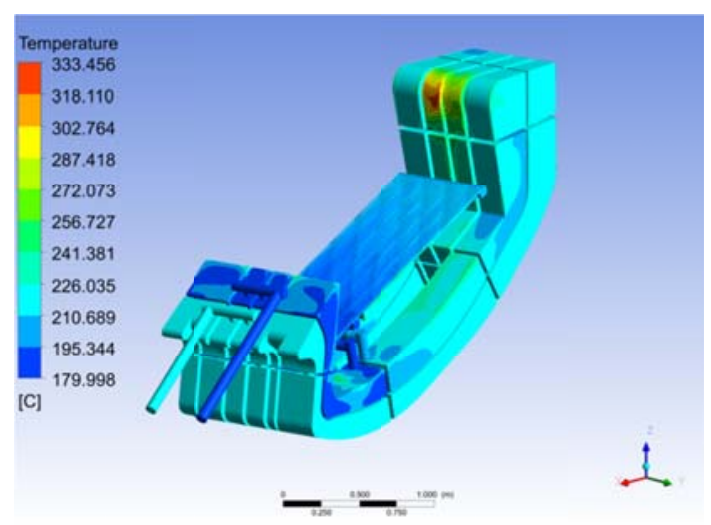

Fig. 6. Coolant temperature field. 


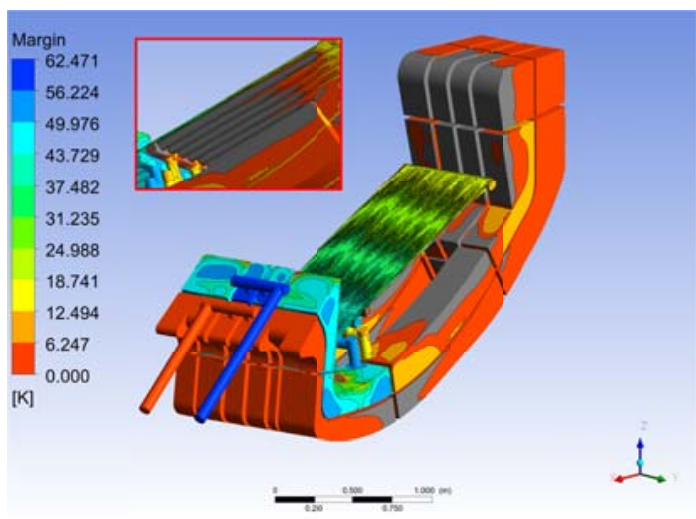

Fig. 7. Coolant margin against saturation field.

In addition, pressure drops along the main sections (Fig. 4) of the CB cooling circuit are reported in Table 6, while bulk temperatures and margins against saturation are shown in Table 7.

Table 6. Coolant total pressure drop distribution.

\begin{tabular}{lcc}
\hline Sections & Pressure Points & $\Delta \mathbf{p}[\mathbf{M P a}]$ \\
\hline $\begin{array}{l}\text { Inlet } \\
\text { Manifold }\end{array}$ & Inlet $\rightarrow$ CB - A & 0.0371 \\
$\begin{array}{l}\text { Upper } \\
\text { Cassette 1 }\end{array}$ & CB - A $\rightarrow$ Liner Inlet & 0.0266 \\
$\begin{array}{l}\text { Liner } \\
\text { Upper } \\
\text { Cassette 2 }\end{array}$ & Liner Inlet $\rightarrow$ Liner Outlet & 1.2305 \\
$\begin{array}{l}\text { Lower } \\
\text { Cassette }\end{array}$ & Liner Outlet $\rightarrow$ CB - B & 0.0199 \\
$\begin{array}{l}\text { Outlet } \\
\text { Manifold }\end{array}$ & CB - C $\rightarrow$ CB - C & 0.0347 \\
Cassette Total & Inlet $\rightarrow$ Outlet & 0.0337 \\
\hline
\end{tabular}

Table 7. Coolant $\mathrm{T}_{\text {bulk }}, \mathrm{T}_{\text {sat }}$ and margin distributions.

\begin{tabular}{lccc}
\hline \multicolumn{1}{c}{ Sections } & $\mathbf{T}_{\text {bulk }}\left[{ }^{\circ} \mathbf{C}\right]$ & $\mathbf{T}_{\text {sat }}\left[{ }^{\circ} \mathbf{C}\right]$ & Margin $\left[{ }^{\circ} \mathbf{C}\right]$ \\
\hline Inlet & 180.00 & 242.56 & 62.56 \\
Outlet & 212.75 & 215.29 & 2.54 \\
Liner Inlet & 185.55 & 241.51 & 55.96 \\
Liner Outlet & 202.13 & 217.39 & 15.27 \\
CB - A & 180.05 & 241.95 & 61.91 \\
CB - B & 210.69 & 216.93 & 6.24 \\
CB - C & 212.76 & 216.10 & 3.34 \\
\hline
\end{tabular}

Even though the maximum temperature calculated $\left(333.5{ }^{\circ} \mathrm{C}\right)$ is significantly higher than the saturation temperature (predicted to range between $\approx 215{ }^{\circ} \mathrm{C}$ and $\approx 243{ }^{\circ} \mathrm{C}$ ), critical areas seem to be localized mainly at the fluid/walls interface, being the bulk temperature always lower than the saturation temperature at the predicted pressure. Nevertheless, the minimum margin against saturation amounts to $\approx 2.5{ }^{\circ} \mathrm{C}$, being sensibly lower than the desired limit of $\approx 20{ }^{\circ} \mathrm{C}$, and it has to be raised by properly increasing the minimum coolant total pressure within the $\mathrm{CB}$ cooling circuit so to increase the \# minimum saturation temperature. In this regard, it has to be highlighted that $\approx 89 \%$ of the overall pressure drop is concentrated within the liner cooling circuit (Table 6), which suggests to check whether there is room to improve its layout, e.g. enllarging its plasma facing channels diameter, so to minimize its contribution to the CB cooling circuit pressure drop. Therefore, attention has been paid to the coolant axial velocity, bulk temperature distributions and CHF margin among the liner channels that have been shown in Figs. 8-11, their key-parameters being reportedl in Tables 8-10.

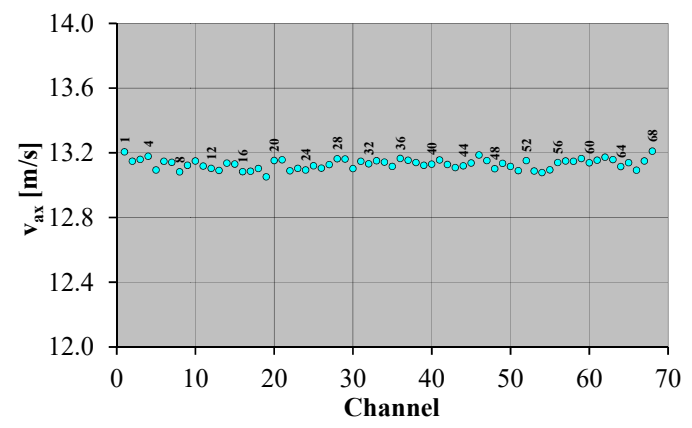

Fig. 8. Coolant $\mathrm{v}_{\mathrm{ax}}$ distribution among liner front channels.

Table 8. Coolant $\mathrm{v}_{\mathrm{ax}}$ distribution key-parameters.

\begin{tabular}{lc}
\hline $\mathbf{v}_{\text {Max }}[\mathbf{m} / \mathbf{s}]$ & 13.209 \\
$\mathbf{v}_{\min }[\mathbf{m} / \mathbf{s}]$ & 13.052 \\
$\boldsymbol{\varepsilon}_{\mathbf{v}}$ & $1.20 \%$ \\
$<\mathbf{v}>[\mathbf{m} / \mathbf{s}]$ & 13.130 \\
$\sigma[\mathbf{m} / \mathbf{s}]$ & 0.031 \\
\hline
\end{tabular}

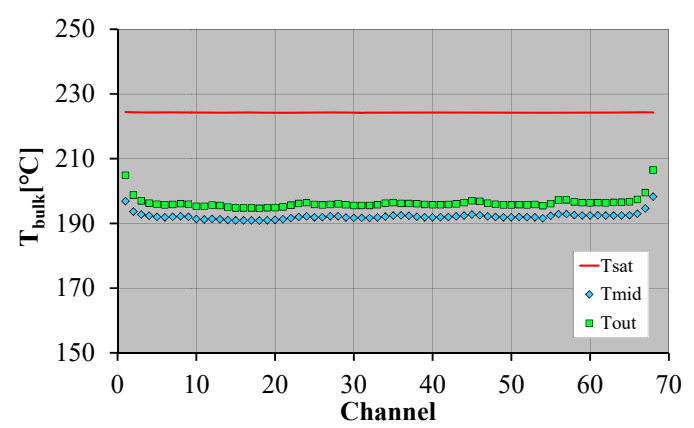

Fig. 9. $\mathrm{T}_{\text {bulk }}$ distribution among liner front channels.

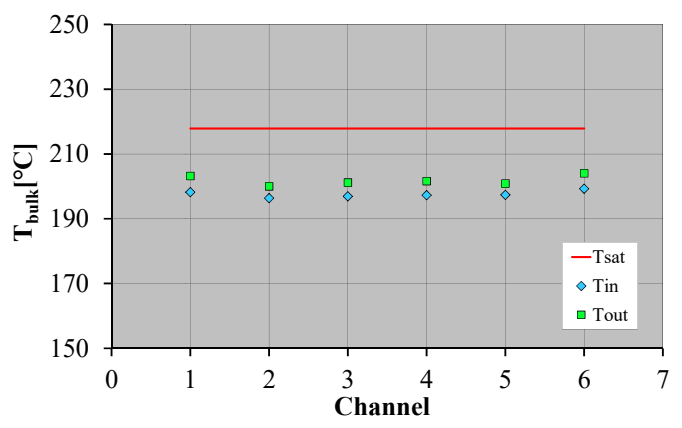

Fig. 10. $\mathrm{T}_{\text {bulk }}$ distribution among liner back channels. 
Table 9. Bulk temperature distributions key-parameters.

\begin{tabular}{lcc}
\hline & $\begin{array}{c}\text { Liner Front } \\
\text { Channels }\end{array}$ & $\begin{array}{c}\text { Liner Back } \\
\text { Channels }\end{array}$ \\
\hline $\mathbf{T}_{\text {Max }}\left[{ }^{\circ} \mathbf{C}\right]$ & 206.48 & 204.04 \\
$\mathbf{T}_{\min }\left[{ }^{\circ} \mathbf{C}\right]$ & 194.66 & 199.99 \\
$\boldsymbol{\varepsilon}_{\mathbf{T}}$ & $5.73 \%$ & $1.98 \%$ \\
$\left\langle\mathbf{T}>\left[{ }^{\circ} \mathbf{C}\right]\right.$ & 196.30 & 201.82 \\
$\boldsymbol{\sigma}$ & 1.837 & 1.522 \\
\hline
\end{tabular}

In particular, the distribution of the margin against CHF onset within the liner plasma facing channels (front channels in Fig. 4) has been assessed mainly in order to check whether its prescribed minimum value of 1.4 is guaranteed by the present layout. To this purpose, attention has been paid to the final sections (front out in Fig. 4) of the liner front channels, where coolant temperature is supposed to reach its maximum value. In these sections, the local values of total pressure, temperature and axial velocity previously calculated have been considered together with the incident heat flux value of $0.5 \mathrm{MW} / \mathrm{m}^{2}$. In these hypotheses, the CHF at the interface between the coolant and the channel walls has been calculated for each channel by means of the proper correlation given in $[21,22]$. An analogous procedure has already been adopted by authors to evaluate the CHF margin distribution of the PFCs cooling circuit [23-25].

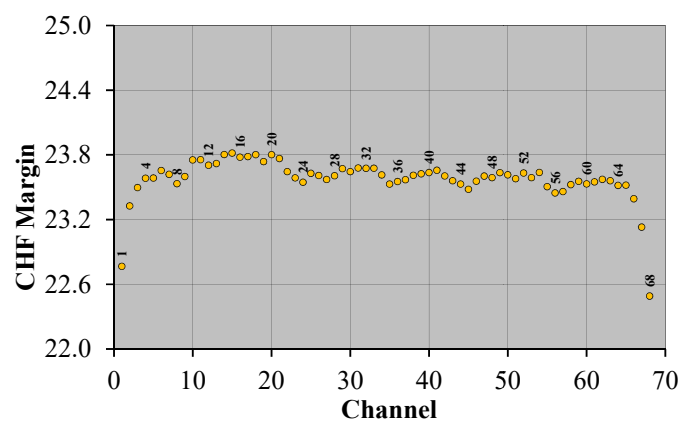

Fig. 11. CHF Margin distribution among Liner front channels.

Table 10. CHF Margin distribution key-parameters.

\begin{tabular}{lc}
\hline (CHF Margin) $)_{\text {Max }}$ & 23.817 \\
${\text { (CHF Margin })_{\min }}$ & 22.491 \\
$\boldsymbol{\varepsilon}_{\mathrm{CHF}}$ & $5.57 \%$ \\
$<$ CHF Margin $>$ & 23.575 \\
$\sigma$ & 0.203 \\
\hline
\end{tabular}

From the analysis of the results obtained for the liner channels, it may be argued that:

- the distribution of coolant axial velocity is considerably uniform, since maximum deviations lower than $2 \%$ have been estimated between the maximum ( $\left.\mathrm{v}_{\mathrm{Max}}\right)$ and minimum $\left(\mathrm{v}_{\min }\right)$ values;

- coolant bulk temperature distributions exhibit a regular behaviour with an acceptable margin against saturation for both front and back channels, whose minimum values $\left(\approx 18^{\circ} \mathrm{C}\right.$ and $\approx 14{ }^{\circ} \mathrm{C}$, , respectively) are slightly lower than the desired limit of $\approx 20{ }^{\circ} \mathrm{C}$;

- CHF margin distribution is significantly higher than prescribed minimum value of 1.4 , its minimum value being equal to 22.5 .

Therefore, a significant margin seems to be available for that strong velocity redluction within liner front channels needed to decrease the pressure drop, thus increasing the margin against saturation $\mathrm{T}_{\text {sat }}-\mathrm{T}$. Specifically, considering that the average liner channel $\Delta \mathrm{p}$ is $\approx 0.64 \mathrm{MPa}$, a slight increase in its diameter (D) from 6 to $8 \mathrm{~mm}$ would almost halve the overall liner $\Delta \mathrm{p}$ as distributed pressure drop is roughly proportional to the fifth power of the channel hydraulic diameter.

Finally, the structure temperature field has been reported in Fig. 12 with a focus on the critical regions where temperature overcomes $550{ }^{\circ} \mathrm{C}$ (grey spots).

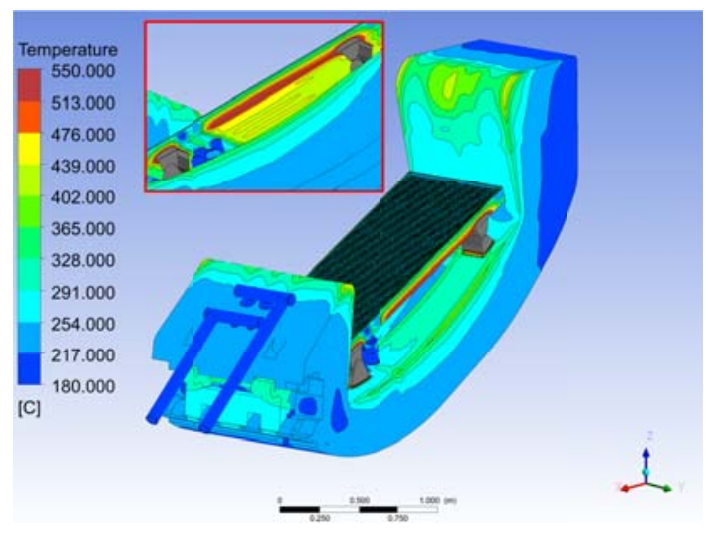

Fig. 12. Structure temperature field.

Results obtained indicate wide critical areas where temperature is predicted to overcome the limit of $550{ }^{\circ} \mathrm{C}$, mainly located, as expected, nearby the liner attachment system, whose layout prevents the coolant to effectively remove nuclear deposited heat power. In particular, a maximum temperature equal to $1419{ }^{\circ} \mathrm{C}$ is predicted, which would certainly jeopardize the integrity of the component, suggesting the need for a further revision of its design. In this respect, the most straightforward and effective solution would be to reduce the volume and, consequently, the thickness of the liner supports so to considerably decrease the maximum temperature.

\section{Conclusions}

Within the framework of the activities foreseen in the WP-DIV1 of the EUROfusion action, a research campaign has been carried out at the University of Palermo, in cooperation with ENEA, to investigate the steady-state thermal-hydraulic performances of the divertor $\mathrm{CB}$ cooling circuit, focussing the attention on the latest design devised in 2018 according to the DEMO Baseline 2017. A theoretical-computational approach based on the Finite Volume Method has been followed 
and a commercial CFD code has been adopted to run a steady-state, fully coupled fluid-structure, thermofluiddynamic analysis of the considered cooling circuit under the nominal operative conditions.

Results obtained have indicated that the CB cooling circuit seems to be able to provide a sufficiently uniform and effective cooling to the main part of the cassette steel structure without overcoming the coolant pressure drop limit of 1.4 MPa. Anyway, some small regions have been observed where the fluid experiences vaporization at the interface with steel walls, suggesting that a further slight revision of the flow path and/or the coolant operative conditions is needed. Moreover, the peculiar structure of the liner supports does not allow them to be properly cooled, resulting in a unviable maximum temperature of $1419^{\circ} \mathrm{C}$. Nevertheless, a straightforward design revision is suggested that would allow to maintain the topology already selected for the supports, while improving their thermal performances.

\section{Acknowledgments}

This work has been carried out within the framework of the EUROfusion Consortium and has received funding from the Euratom research and training programme 2014-2018 and 2019-2020 under grant agreement No 633053. The views and opinions expressed herein do not necessarily reflect those of the European Commission.

\section{References}

[1] T. Donné et al., European Research Roadmap to the Realisation of Fusion Energy, EUROfusion, 2018, ISBN 978-3-00-061152-0.

[2] J.H. You et al., Conceptual design studies for the European DEMO divertor: Rationale and first results, Fusion Eng. Des. 109-111 (2016) 1598-1603, http://dx.doi.org/10.1016/j.fusengdes.2015.11.012.

[3] J.H. You et al., Progress in the initial design activities for the European DEMO divertor: Subproject "Cassette", Fusion Eng. Des. 124 (2017) 364-370, http://dx.doi.org/10.1016/j.fusengdes.2017.03.018.

[4] P.A. Di Maio et al., Thermal-hydraulic optimisation of the DEMO divertor cassette body cooling circuit equipped with a liner, Fusion Eng. Des. 146 (2019) 220223, http://dx.doi.org/10.1016/j.fusengdes.2018.12.024.

[5] P.A. Di Maio et al., Computational thermofluid-dynamic analysis of DEMO divertor cassette body cooling circuit, Fusion Eng. Des. $136 \quad$ (2018) 1588-1592, http://dx.doi.org/10.1016/j.fusengdes.2018.05.063.

[6] P.A. Di Maio et al., Analysis of steady state thermalhydraulic behaviour of the DEMO divertor cassette body cooling circuit, Fusion Eng. Des. 124 (2017) 437-441, http://dx.doi.org/10.1016/j.fusengdes.2017.02.012.

[7] ANSYS Inc., ANSYS CFX-Solver Theory Guide, Release 2019 R1, January 2019.

[8] P.A. Di Maio et al., On the hydraulic behaviour of ITER Shield Blocks \#14 and \#08. Computational analysis and comparison with experimental tests, Fusion Eng. Des. 109-111 (2016) 30-36, http://dx.doi.org/10.1016/j.fusengdes.2016.03.060.

[9] P.A. Di Maio et al., Analysis of the steady state hydraulic behaviour of the ITER blanket cooling system, Fusion Eng. Des. 98-99 (2015) 1470-1473, http://dx.doi.org/10.1016/j.fusengdes.2015.05.070.

[10] P.A. Di Maio et al., Numerical simulation of the transient thermal-hydraulic behaviour of the ITER blanket cooling system under the draining operational procedure, Fusion Eng. Des. $\quad 98-99 \quad$ (2015) 1664-1667, http://dx.doi.org/10.1016/j.fusengdes.2015.01.024.

[11] C. Gliss, DEMO Baseline Model 2017. EUROfusion IDM Ref. 2N4EZW.

[12] D. Marzullo et al., Progress in the pre-conceptual CAD engineering of European DEMO divertor cassette, Fusion Eng. Des. $146 \quad$ (2019) 942-945, https://doi.org/10.1016/j.fusengdes.2019.01.120.

[13] G. Mazzone et al., Eurofusion-DEMO Divertor - Cassette Design and Integration, this conference.

[14] International Association for the Properties of Water and Steam, Revised Release on the IAPWS Industrial Formulation 1997 for the Thermodynamic Properties of Water and Steam, Lucerne, Switzerland, 2007.

[15] MAT-1.2.1-T2-D1 Material Property Handbook pilot project on EUROFER97 (MTA EK, KIT), EUROfusion IDM: EFDA_D_2MRP77 v1.0.

[16] ITER Material Properties Handbook, ITER Document No. G74 MA 16.

[17] WPDIV-1-T005 Loads Specification (LS) for Divertor Cassette 2018 (incl. neutronics, EM analysis), EUROfusion IDM: EFDA_D_2NLWLE v1.0.

[18] T. Haertl et al., Rationale for the selection of the operating temperature of the DEMO vacuum vessel, Fusion Eng. Des. 146 (2019) 1096-1099, https://doi.org/10.1016/j.fusengdes.2019.02.014.

[19] B. Van der Schaaf et al., The development of EUROFER reduced activation steel, Fusion Eng. Des. 69 (2003) 197 203, https://doi.org/10.1016/S0920-3796(03)00337-5.

[20] P.J. Linstrom and W.G. Mallard, Eds., NIST Chemistry WebBook, NIST Standard Reference Database Number 69, National Institute of Standards and Technology, Gaithersburg MD, 20899, https://doi.org/10.18434/T4D303, (retrieved September 9, 2019).

[21] I Smid et al., Comparison between various thermal hydraulic tube concepts for the ITER divertor, Fusion Technology (1996) 263-266.

[22] A.R. Raffray et al., Critical heat flux analysis and R\&D for the design of the ITER divertor, Fusion Eng. Des. 45 (1999) 377-407, https://doi.org/10.1016/S09203796(99)00053-8.

[23] P.A. Di Maio et al., Hydraulic analysis of EU-DEMO divertor plasma facing components cooling circuit under nominal operating scenarios, Fusion Eng. Des., article in press, https://doi.org/10.1016/j.fusengdes.2019.03.030.

[24] P.A. Di Maio et al., On the thermal-hydraulic optimization of DEMO divertor plasma facing components cooling circuit, Fusion Eng. Des. 136 (2018) 1438-1443, https://doi.org/10.1016/j.fusengdes.2018.05.032.

[25] P.A. Di Maio et al., Thermal-hydraulic behaviour of the DEMO divertor plasma facing components cooling circuit, Fusion Eng. Des. 124 (2017) 415-419, https://doi.org/10.1016/j.fusengdes.2017.02.025. 